\title{
TERPENOIDS FROM CALOCEDRUS FORMOSANA
}

\author{
Jim-Min Fang, Shyi-Tal Jan and Yu-Shia Cheng * \\ Department of Chemistry, National Taiwan University, Taipei, Taiwan, Republic of China
}

(Received 27 June 1986)

Key Wond Index Calocedrus formosana; Cupressaceac; wood; 1-oxohinokiol; naphthaldehyde sesquiterpene; naphthoate sesquiterpene: 3,4-dihydro analogues; hinokiol; shonanol.

Abatract-A novel diterpene, 1-oxohinokiol was isolated from the acetone extract of the wood of $C$. formosana. Four novel sesquiterpenes, 5-methyl-8-isopropyl-2-naphthalenecarboxaldehyde, methyl 5-methyl-8-isopropyl-2naphthalenocarboxylate and their 3,4-dihydro anatogues were also isolated. The structural assignments were based on the spectroscopic analysis and confirmed by chemical correlation.

\section{INTRODLCTION}

Calocedrus formosana, a member of the Cupressaceae, is an economically important tree indigenous to Taiwan [1]. In a recent sludy of the constituents of the wood, we found a lignan dihydroanhydride, namely $(+$-calocedrin [2]. We report now some novel terpenoid constituents isolated from the wood.

\section{RESUI.TS AND DISCLSSION}

The acetone extract of the wood of $C$. formosana was subjected to chromatography on silica gel. The terpenoidal components 17 were isolated by clution with gradients of hexane-ethyl acetate. Compound $1 . \mathrm{M}^{*}$ at $m / z 212$, showed an IR absorption at $1685 \mathrm{~cm}^{-1}$ attributable to a conjugated carbonyl group. The 'HNMR spectrum of 1 cxhibited the resonances of an aromatic methyl group $(\delta 2.70, s)$, an aldehyde group $(\delta 10.20$, s), an isopropyl group and five aromatic protons. Compound 1 was recognized as the sesquiterpene 5-methyl-8isopropyl-2-naphthalenocarboxaldehyde; this is the first report of its occurrence in nature although a synthetic sample has been reported [3]. Compound 2, $M^{*}$ at $m ; z$ 214, also showed the IR absorption $(1665 \mathrm{~cm}$ ') of a conjugated carbonyl group. The 'HNMR spectrum revealed characteristic resonances of an aromatic methyl $(\delta 2.28, s)$, an isopropyl group, an olefinic proton $(\delta 7.64, s)$ an aldehyde proton $(\delta 9.70, s)$ and two ortho-aromatic protons. Compound 2 was readily transformed into compound 1 by oxidation with chloranil in refluxing benzene. Thus, the structure of compound 2 was confirmed to be the 3,4-dihydro analogue of 1 . Compound 3 , $M^{*}$ at $m_{i}=242$. was recognized as a methyl ester of an aromatic acid as evidenced by the IR absorption at $1720 \mathrm{~cm}$ ' and the characteristic resonance of a methyl group at $\delta 3.99(\mathrm{~s})$ in the 'H NMR spectrum. The structure of 3 was revealed to be closely related to that of 1 by comparison of their 'H NMR spectra. Reduction of ester 3 (LiAlH $\left.. . \mathrm{Et}_{2} \mathrm{O}, 0^{\circ}\right)$ gave an alcohol product, which was then oxidized by manganese dioxide (hexane, $25^{\circ}$ ) to afford compound 1 . The novel natural sesquiterpene 3 was thus determined to be methyl 5-methyl-8-isopropyl2-naphthalene carboxylate. Compound $4, M^{\circ}$ at $m / z 244$,

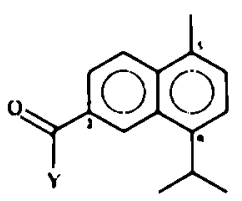

$1 Y=H$

$3 Y=$ OCH,<smiles>[Y]C1=C[C@H](O)[C@@H](C)[C@@H]2CCc3cc(C(C)C)c(O)cc3[C@]12C</smiles>

$5 Y \cdot H \cdot M$

$7 Y=O$

was also a methyl ester as revealed by the IR absorption at $1710 \mathrm{~cm}$ ' and the resonance of a methyl group at $\delta 3.83$ (5). By comparison of the 'HNMR spectrum of 4 with those of 2 and 3 , the structure of 4 was inferred to be the 3,4-dihydro analogue of 3. Compound 4 was oxidized to 3 by chloranil, and thus the structural assignment was confirmed.

Compound $5, M^{\circ}$ at $m / 2302$, and compound $6, M^{\bullet}$ at $m / z 298$, were identified as $(+$-hinokiol [4] and $(+)$ shonanol [5], respectively, by the evidence of the optical rotations and their spectroscopic properties. Compound 7. $M^{\circ}$ at $m / z 316$. $[x]_{\mathrm{D}}^{23}+130^{\circ}$ (c 0.68 , acelone) was isolated as colourless crystals, mp $228.229^{\circ}$. The IR spectrum of 7 exhibited absorptions at 1710 and $3540 \mathrm{~cm}$ ' attributable to the carbonyl and hydroxyl groups. The 'H NMR spectrum of 7 revealed five methyl groups appearing at $\delta 1.10(s), 1.13(s), 1.20(d, J=7 \mathrm{~Hz}$ ). $1.23(d, J=7 \mathrm{~Hz})$ and $1.55(s)$. The signals at $\delta 6.83(s)$ and 6.97 (s) were attributable to the resonances of two paraaromatic protons. Based on the above data, compound 7 
was inferred to have the abietane-type structure related to those of hinokiol and shonanol. Treatment of 7 with a catalytic amount of p-toluenesulphonic acid in refluxing benzene yielded a dehydration product $(77 \%$, which was identified as $(t)$-shonanol by comparison of the physical and spectroscopic properties (mp, [ $\alpha$ ], TLC, IR, MS and ' $H$ NMR). Therefore, compound 7 was determined to be $(++1$-oxohinokiol with a C-3 hydroxyl group at the $\beta$ position. The corresponding resonance of the axial proton occurred at $\delta 3.70$ (dd, $J=10,5 \mathrm{~Hz}$ ).

\section{EXPERIMENTAI.}

Plant maserial. Calocedrus formosano (Florin) Florin was collected in the campus of the National Taiwan University. The skinned and air-dried wood $(600 \mathrm{~g})$ from brancties $6.8 \mathrm{~cm}$ in diam. was selected for study. After extraction $\times 3$ with $\mathrm{Me}_{2} \mathrm{CO}$. the combined extracts were concd in cacuo to give $20 \mathrm{~g}$ of residue. Components were separated by $\mathrm{CC}$ on silica gel $(230 \mathrm{~g})$ and elution with hexane EtOAc gradients.

S-Meihyl-8-isopropyl-2-naphehalenecarboxaldehyde $R, 0.42$ (EIOAC hexane, 2:98). LV $i_{\max }^{\text {CHCl, }} \mathrm{nm}(\varepsilon): 251$ (16 580). 294 (6470) 301 (5490) 350 (2890) 357 (2970). IR r 2715, 1685. MS m/z (rel. int.) 212 [M] ' (54) 197 (100) 154 (21) ${ }^{1} \mathrm{H}$ NMR $\left(\mathrm{CDCl}_{3}, 400 \mathrm{MHz}\right.$.). $\delta 1.4316 \mathrm{H}, d . J=6.8 \mathrm{~Hz}$, $2.70(3 \mathrm{H}$, s) $3.84(1 \mathrm{H}$, septet, $J=6.8 \mathrm{~Hz}, 7.42(1 \mathrm{H}, d, J=7.2 \mathrm{~Hz} \mathrm{H}-7) .7 .46$ $(1 \mathrm{H}, d, J=7.2 \mathrm{~Hz}, \mathrm{H}-6), 7.98(1 \mathrm{H}, d d, J=8.8,1.2 \mathrm{~Hz}, \mathrm{H}-3), 8.13$ $(1 H, d, J=8.8 \mathrm{~Hz}, \mathrm{H}-4)_{1} 8.66(1 \mathrm{H}, d, J=1.2 \mathrm{~Hz}, \mathrm{H}-1), 10.20(1 \mathrm{H}$, s, $\mathrm{CHO}$ ).

3.4-Dihydro-5-methyl-8-isopropyl-2-naphihalenecarboxalde hyde (2). $R, 0.41$ (EtOAc-hexane 2:98). LV i $(H C), \mathrm{nm}(\varepsilon): 241$

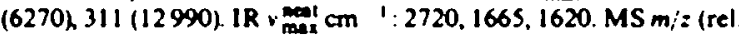
int.t $214[\mathrm{M}]^{\circ}$ (65) 199 (100) 171 (50) 143 (65) 128 (35) 'HNMR $(C D C l,, 400 \mathrm{MHz}): \delta 1.28\left(6 \mathrm{H}, d, J=7 \mathrm{~Hz},{ }_{2} .28(3 \mathrm{H}\right.$, s), $2.52(2 \mathrm{H}, d d, J=8.8 \mathrm{~Hz}, \mathrm{H} \cdot 3), 2.79(2 \mathrm{H}, d d, J=8.8 \mathrm{~Hz}, \mathrm{H}-4)$ $3.36(1 \mathrm{H}$, seplet, $J=7 \mathrm{~Hz}, 7.12(\mathrm{IH}, d, J=8 \mathrm{~Hz}, \mathrm{H}-7), 7.18(1 \mathrm{H}$, d. $J=8 \mathrm{~Hz}, \mathrm{H} \cdot 6 \mathrm{~L} 7.64$ (1H, s. H.1L 9.70 (1H, s. CHO).

Methyl S-methyl-8-isopropyl-2-naphthalenecarboxylate (3)
$R_{f} 0.45$ (ElOAC hexane, 2:98). UV $\lambda_{\text {mea }}^{\text {CHC }} \mathrm{nm}(\ell) .248$ (13810) 292 (4240) 302 (3600) 330 (1840) 342 (2010). IR v 1720. MS m/z (rel. int.) 242 [M] ${ }^{*}(60), 227$ (100), 211 (7), 195 (5) 183 (3). 168 (26). 153 (16). 'H NMR (CDCl, 400 MHzk $\delta 1.40$ (6H.d.J $=6.7 \mathrm{~Hz}$. . $2.68(3 \mathrm{H}$, s). $3.83(1 \mathrm{H}$, sepiel, $\mathrm{J}=6.7 \mathrm{~Hz}), 3.99$ (3H, s, $\mathrm{CO}_{2} \mathrm{CH}_{3}$ ) 7.37 (1H, d. J = $7.5 \mathrm{~Hz}, \mathrm{H} \cdot 7 \mathrm{~h}, 7.40$ (1H. d. J $=7.5 \mathrm{~Hz}, \mathrm{H} \cdot 6$ ). 8.05 (1H. $d . J=8.7 \mathrm{~Hz} \mathrm{H}-4$ ) 8.09 (1H. dd, $J$ $=8.7 .1 .7 \mathrm{~Hz}, \mathrm{H}-31,8.93\left(1 \mathrm{H}, d_{,} \mathrm{J}=1.7 \mathrm{~Hz} \mathrm{H}-1\right)$.

Methyl 3,4-dihydro-5-methyl-8-isopropyl-2-naphthalene. carboxylate (4). $R, 0.42$ (EIOAc -hexane, 2:98). LV ; CHCI, $\mathrm{nm}$

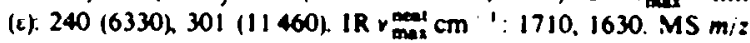
(rel. int.) $244[\mathrm{M}]^{\circ}(93), 229$ (100), 213 (23), 212 (28), 201 (1S) 197 (43), 185 (15) 169 (48), 154 (28), 143 (40). 'H NMR (CDCl, $400 \mathrm{MHz}$ ): $\delta 1.25(6 \mathrm{H}, d . J=7 \mathrm{~Hz}) .2 .26(3 \mathrm{H}, \mathrm{s}) .2 .55(2 \mathrm{H}, \mathrm{dd}, \mathrm{J}$ $=8,8 \mathrm{~Hz}, \mathrm{H}-3 \mathrm{~h}, 2.78(2 \mathrm{H}, \mathrm{dd}, J=8,8 \mathrm{~Hz} \mathrm{H}-4), 3.34(1 \mathrm{H}$, septet, $J=7 \mathrm{~Hz}$ ) $3.83\left(3 \mathrm{H}\right.$, s. $\mathrm{CO}_{2} \mathrm{CH}_{3}, 7.08(1 \mathrm{H}, \mathrm{d}, \mathrm{J}=8 \mathrm{~Hz}, \mathrm{H}-7$ ) $7.12(1 \mathrm{H}, d, J-8 \mathrm{~Hz}, \mathrm{H}-6), 7.91(1 \mathrm{H}, \mathrm{s}, \mathrm{H}-1)$.

(+H-Oxohinokiol (7). Colourless crystals, mp 228229 . [a] b" + 130" ic 0.08: $\mathrm{Me}_{2} \mathrm{CO}$ ) $R, 0.27$ (bexane $\mathrm{Me}_{2} \mathrm{CO}, 7: 3$ ).

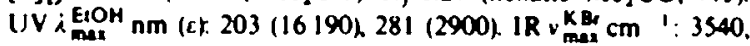
3300, 1710. MS miz (rel. Int.t $316[\mathrm{M}]^{\cdot}(100), 301$ (43), 243 (93) 'H NMR ICDCl, 90 MHz) $\delta 1.10$ (3H. s). 1.13 (3H. s). 1.20 (3H, d. $J=7 \mathrm{~Hz}$. $1.23(3 \mathrm{H}, d . J=7 \mathrm{Hzh} 1.55(3 \mathrm{H}$, sh. $3.18(1 \mathrm{H}, m) .3 .70$ (1H, dd, $J=10,5 \mathrm{~Hz}, \mathrm{H}-3 \mathrm{~h}, 6.83$ (1H, sh. 6.97 (1H, s).

Acknowledgement The authors wish to thank the National Science Council (ROC) for financial support.

\section{REFERENCES}

1. Flora of Taiwan (1975) Vol. I. p. 538. Epoch, Taiwan.

2. Fang. J. M., Jan, S. T. and Cheng. Y. S. (1985) Phytochemistry 24. 1863.

3. Reddy, N. P. and Rao, G. S. K. (1982) Indian J. Chem. 21 R, 885

4. Cheng. Y. S. and Lin. K. C. (1971) Chemistry (Chinese) 94.

S. Matsumoto, T. Imai, S. Kawashima, $H$ and Mitsuki, M (1981) Bull. Chem. Sac. Jpn. 54. 2099. 